\title{
UNHA REFLEXIÓN SOBRE A HISTORIA CRITICA DE CANTARES GALLEGOS: A OBRA DE ROSALÍA BAIXO A LUZ DOS NOVOS PARADIGMAS CRÍTICOS
}

María López Sández

Universidade de Santiago de Compostela

doi: 10.17075/rcsxxi.2014.044

\section{CONSELLO}

DA CULTURA

GALEGA 



\section{CANTARES GALLEGOS E FOLLAS NOVAS: UNHA HISTORIA CRÍ- TICA ENFRONTADA}

A recepción popular e a historia crítica de Cantares gallegos (1863) resume, mellor cá de calquera outra obra de Rosalía de Castro, a evolución na apreciación da propia figura da escritora galega. Obra fundacional pola súa data de creación e base en que se asenta a implicación emocional do pobo galego con Rosalía, Cantares gallegos foi, tamén, a súa publicación máis sometida a procesos de folclorización (Figueroa 1998) e a máis utilizada para unha neutralización ideolóxica do potencial subversivo da obra rosaliana.

Mais os últimos avances e perspectivas teóricas atoparon nela unha referencia fundamental de signo ben distinto. A visión de Rosalía como inauguradora do ensaio galego, defendida por García Negro (2010), ten un argumento clave na magnífica peza prologal de Cantares gallegos, que concitou un enorme interese crítico nos últimos tempos, tamén desde a perspectiva do xénero do manifesto literario (Sobrino Freire 2009). Por outra banda, a análise de Cantares gallegos como peza retórica que mudou e marcou a traxectoria dun novo imaxinario paisaxístico (López Sández 2006, 2008) atopou nesta obra unha engrenaxe retórica caracterizada esencialmente pola súa eficacia. Na mesma lińa, os achegamentos ao estudo da prosa de Rosalía salientaron relacións intertextuais como as existentes entre o comezo de Flavio (1861) e o cantar 15 ("Adios ríos, adiós fontes»), cun suxestivo e significativo valor invertido. Mesmo as actualizacións interartísticas seguen revisitando os Cantares desde novos parámetros estéticos que, lonxe de lles imporen unha vangarda allea a eles, semellan revelar o que de innovador e subversivo agochaban xa orixinariamente. Sirvan de exemplo os achegamentos desde o «hip-hop» e as declaracións en que a cantante viguesa Aid afirmaba que se pode dicir que Rosalía de Castro cultivou este xénero (La Voz de Galicia 2/06/2013).

Existe, daquela, un paralelismo entre a historia crítica de Cantares gallegos e a propia evolución do papel de Rosalía de Castro dentro do sistema literario galego. A actual revitalización no estudo crítico desta obra, da que este mesmo congreso 
ou a edición de Cantares gallegos a cargo de Anxo Angueira son proba (a efeméride é máis neste caso un pretexto ca unha causa), vén a romper cunha polarización que dividiu, tradicionalmente, a crítica segundo a maior inclinación cara a un ou outro poemario galego de Rosalía en asociación cunha perspectiva ideolóxica e un xuízo do papel que cabía outorgarlle no conxunto do canon literario. Asentáronse, así, xa nunha primeira fase do proceso de recepción, moitos dos procesos que caracterizarían posteriormente a análise da obra de Rosalía: mecanismos de simplificación, de redución ao paradigma romántico, ao local, de asociación co sentimental e irracional ou co popular e espontáneo e, en definitiva, ideas reforzadas pola confluencia cos valores asociados ao patrón de xénero feminino.

Neste sentido, tivo especial relevancia o cońecido posicionamento de Emilia Pardo Bazán en De mi tierra (1888), considerando a poesía de inspiración popular a mellor de Rosalía. A intencionalidade que subxace a este xuízo crítico (que ten na súa base un forte prexuízo sociolingüístico) é a de neutralizar e desactivar e, en último termo, minimizar a propia relevancia da figura de Rosalía e a súa subversión ideolóxica. Por máis que, como sinalou Carvalho Calero na súa Historia da literatura galega (1963: 185), haxa certa lóxica en que na época do realismo a inclinación sexa cara a Cantares gallegos, do mesmo xeito que o trasfondo existencialista dos anos 50 vai favorecer a predilección pola Rosalía máis metafísica, non se nos oculta que están implicadas, nesta rede de asociacións, dicotomías como a do local fronte ao universal ou o espontáneo e popular fronte ao profundo e transcendente, que implican parámetros de calidade contrarios na apreciación estética que tende a usarse para a canonización nun plano universal e para a relevancia concedida a un escritor.

O posicionamento contrario, aquel que considera a Follas novas (1880) a obra cimeira de Rosalía, ten na Xeración de Galaxia o máximo e máis explícito expoñente. A forte valorización que a Xeración dos 50 fixo de Follas novas (plasmada nos 7 ensayos sobre Rosalía e continuadora da postura de Murguía) procuraba engrandecer a figura da autora a través dun tema central prestixiado na tradición poética occidental: o da reflexión existencial. Á potenciación da dimensión local, popular, xeograficamente situada, e, daquela, limitada multiplemente no xeográfico e social, opoñíase agora a validez e relevancia universal. No último dos 7 ensayos sobre Rosalía (1952), Francisco Fernández del Riego, baixo o pseudónimo de Salvador Lorenzana, sintetizou deste xeito o debate: 
A disparidade de opinións xurde no intre de valorar a superioridade antre os seus libros. Esiste case unha identificación total en considerar millor a producción en galego que a obra en castelán. Pero o disentimento maniféstase na estimanza sobre a prioridade lírica antre Cantares e Follas. Pra uns superan, poéticamente, os primeiros ás segundas. Pra outros, a orde de valoración é inversa.

Ó noso ver, Follas Novas é a suprema obra, na creación enxebremente lírica, de Rosalía. Cantares gallegos — pensamos con César Barja — é un libro de sentimento. [...] Follas Novas non é un libro tan popular como Cantares. É máis persoal, máis subxetivo, máis de Rosalía mesma (Lorenzana 1952: 170).

Neste traballo, significativamente titulado "Xuízos Críticos sobre Rosalía», o propio Fernández del Riego dá a clave da razón última deste posicionamento que resume o da súa Xeración: ao facer o repaso do xuízo crítico sobre Rosalía sinala o corte radical que supuxo o franquismo. Ese é o contexto que, unido ao auxe do existencialismo e á idea de Galaxia de provocar o espertar cultural de Galicia, fixo que se interpretase a poesía máis filosófica de Rosalía como unha canle de reivindicación e de elevación da súa figura cara a unha dimensión universal. Por outra parte, a cuestión lingüística volve ser igualmente relevante, ao se tratar de demostrar a validez do galego para a expresión dos máis sublimes pensamentos filosóficos.

O posicionamento de Carvalho Calero na súa Historia da literatura galega (1963) adopta, en certo xeito, unha postura de síntese respecto aos dous patróns previos. Sendo un autor que non dubida á hora de estabelecer xerarquías (algo que se pode exemplificar coa súa afirmación categórica da preeminencia de Rosalía entre os autores do Rexurdimento), opta por unha postura de equilibrio no xuízo sobre as dúas obras. Malia reapareceren, no seu discurso, dicotomías como a da poesía popular fronte ao "acento universal» ou a do "vieiro do particularismo e o vieiro do universalismo» (183), cando enfronta o debate sobre a primacía dunha ou doutra obra resólveo definindo a Rosalía como «un gran poeta doble, ao que hai que considerar na súa totalidade» (185). E mesmo insistindo no particularismo de Cantares: "Só o pobo galego pode gozar en toda a súa plenitude disa poesía. [...] Non é unha poesía de base cultural, académica ou histórica, senón de base folclórica e natural» (173), é categórico ao empregar expresións como 
«primeiro fito inconmovibre na historia da literatura galega contemporánea» ou «obra maestra» (145).

\section{A REVALORIZACIÓN DE ROSALÍA COMO CONSECUENCIA DAAPA- RICIÓN DOS NOVOS PARADIGMAS CRÍTICOS}

A maior achega recente ao estudo de Cantares gallegos radica na superación da dicotomía que marcou a historia da crítica rosaliana á que fixemos referencia anteriormente. No estudo introdutorio á edición desta obra, Anxo Angueira (2013) salientou aspectos como o entroncamento con Sarmiento, o carácter dialóxico da obra e as viraxes ou afastamentos das fontes populares para orientarse cara a uns principios e un ideario literario e político persoal. Mesmo, de xeito moi persuasivo, analizou o feminismo de Cantares gallegos, quizais un dos únicos aspectos en que a análise crítica desta obra se afastou das tendencias xerais nos estudos rosalianos; pois, malia o forte desenvolvemento da crítica feminista a propósito do conxunto da obra, son poucos os estudos previos, coa excepción do de Carlos Feal Deibe (1986), que se centran nesta cuestión a propósito dos Cantares (Anxo angueira 2013). Como se sinalou, moi suxestivamente, neste estudo preliminar, a obra instaura un suxeito literario e político cun forte protagonismo feminino; non hai nela, propiamente, temática amorosa, senón a problematización do papel feminino na sociedade, en consonancia coa forte pegada desta cuestión no conxunto da obra rosaliana. Só vencido, xa que logo, o prexuízo valorativo do popular, espontáneo e folclórico, revelaron os Cantares toda a súa forza, subversión, intelixencia e calidade poética.

A sombra deste debate é moi vizosa e a superación das ideas que asentou sobre Cantares gallegos procedeu, en boa medida, de estudos non centrados especificamente nesta obra, malia que as recentes perspectivas teóricas atoparon novamente nos Cantares unha referencia fundamental. Deterémonos agora nalgunha destas cuestións que, a modo de exemplo das últimas achegas arredor de Cantares gallegos, conflúen en conxunto na construción dunha imaxe moito máis complexa e suxestiva da que a visión tradicional permitiu ver. 


\section{CANTARES GALLEGOS E A ROSALÍA ENSAÍSTA: A SUPERACIÓN DA VISIÓN FOLCLORIZANTE}

García Negro (2010) concedeulle un lugar certamente relevante á análise do prólogo de Cantares gallegos, «o primeiro texto en prosa galega da autora (ou, desde logo, o primeiro cońecido), con todas as características retóricas que podemos atribuír a un ensaio derivado dun texto complexo, que até agora lemos como unha alegación [...], como o discurso de defensa dun, na altura, bo avogado defensor perante un tribunal hostil ou indiferente á causa da defendida» (57). Mais as visións reducionistas e folclorizantes do poemario apenas repararon neste texto. No congreso da Asociación Internacional de Estudos Galegos que tivo lugar en Cardiff en setembro de 2012, analizamos esta dimensión ensaística da produción rosaliana, detectando un forte pulo na súa obra cara á expresión dun marcado posicionamento ideolóxico. Pero se mesmo a escrita literaria implicaba problemas, como sinalou Rosalía en «Las literatas» (1865), cabe imaxinar a ousadía da expresión directa do pensamento que supón calquera das vertentes do ensaio. Esta é a causa, como se ten analizado, da forte presenza da captatio benevolentiae e a retórica da modestia nos seus prólogos e nos artigos en prensa e, tamén, como entón nos ocupamos de analizar, da inserción dun subtexto ensaístico na produción en prosa, a través das inxerencias autoriais, os elementos paratextuais e as partes monologadas ou dialóxicas que se achegan ao molde ensaístico. Textos narrativos breves como Ruinas, «El cadiceño» e "Conto gallego» están claramente postos ao servizo da expresión de ideas. Baixo a protección que outorga a ficción, reborda un discurso ideolóxico que se expresa nos paratextos, nas frecuentes incursións da autora implícita, na tendencia apreciativa das voces narradoras, en monólogos fortemente argumentativos ou en diálogos en que se contrapoñen evidentes posicionamentos ideolóxicos. Este subtexto ensaístico que podemos detectar na obra de Rosalía trata recorrentemente un conxunto de temas, como son a cuestión de xénero, a dimensión ética e social e a reflexión verbo da propia creación literaria e acerca dos temas existenciais. Os fenómenos de aculturación, as supersticións populares e mais a análise das categorías estéticas son outros temas que, con menor grao de recorrencia, aparecen tamén cun tratamento reflexivo dentro da súa produción en prosa. A aparición de certas preocupacións en textos distintos (ás veces, a través de personaxes; outras, por 
medio de incursións autoriais, en prólogos ou outros elementos paratextuais) dá como resultado unha visión complexa, polifónica e ambigua, que chega mesmo á contradición.

En toda esta dimensión ensaística e ideolóxica, o prólogo de Cantares gallegos ocupa un lugar moi destacado por ser o primeiro desta natureza en lingua galega e pertencer a unha obra que inaugura unha nova época e abre un camińo de reivindicación lingüística, antropolóxica e paisaxística. Non semella atribuíbel a unha rebordadura emocional, como se ten suxerido, esta tendencia á irrupción autorial, senón máis ben a un de signo intelectual e ideolóxico que cómpre vincular con esa Rosalía ensaísta que non puido ser porque, como ela mesma remata dicindo no prólogo a La hija del mar, "todavía no les es permitido a las mujeres escribir lo que sienten y lo que saben» (1959: 20). Pór a énfase no limiar de Cantares gallegos racha, así, coas visións folclorizantes e popularizantes de Rosalía, potencia a súa dimensión ideolóxica e ensaística e matiza, en definitiva, a súa asociación cos valores femininos do emocional e o irracional, ao introducir, a través do discurso expositivo e ensaístico, posicionamentos máis vinculados á tipoloxía racional e ao coñecemento e a ideoloxía.

Un segundo aspecto das novas perspectivas críticas arredor de Rosalía que acabou deitando nova luz sobre Cantares gallegos é a atención ao conxunto da súa obra. Fronte aos parcelamentos que tradicionalmente se fixeron (concretamente da súa prosa), apóstase agora por unha visión máis global, atenta ás relacións e aos contrastes. Esta semella unha perspectiva fértil, porque son moitas as cuestións que se poden sinalar a este respecto. Un exemplo sería a do Cantar $15^{\circ}$, "Adiós ríos, adiós fontes», que ten no comezo de Flavio unha curiosa inversión intertextual:

Adiós, pues, lugares a quien no amo.

Casa que me ha visto nacer.

Jardín en donde por primera vez aspiré el aroma de las flores.

Fuentes cristalinas, bosque umbroso, en donde gemía el viento en las tardes del invierno, prado sonriente bañado por el primer rayo del sol, ¡adiós!

(1861: 251) 
Semellante contraste é o que se estabelece entre o espazo representado en Cantares gallegos e a poética do deserto, a paisaxe desolada e inserida na categoría romántica do sublime que se atopa en La hija del mar, tal como analizou Margarita García Candeira (2012) nun artigo inserido nun volume conxunto dedicado ao estudo da obra narrativa de Rosalía de Castro. O efecto de atopar no seo da obra de Rosalía estas inversións, un gusto polo xogo de contrarios e contradicións, racha coa visión dunha efusión simple e directa e contribúe a construír unha imaxe máis complexa na que non están ausentes as ambigüidades e as tensións.

\section{CANTARES GALLEGOS Á LUZ DOS ESTUDOS SOBRE O IMAXINA- RIO}

Outra esfera desde a que se contrarrestou esa imaxe dunha Rosalía como autora dunha obra popular, espontánea e sinxela é a dos estudos sobre o imaxinario. En traballos previos (López Sández 2006, 2008), focalizamos a nosa análise sobre a potencialidade da descrición e os mecanismos representacionais para modificar os imaxinarios sociais poñendo a énfase precisamente en Cantares gallegos. A súa oposición a un discurso previo disfórico sobre Galicia (o "cortello inmundo» ao que alude no prólogo da obra citada), o feito de que parta dun case baleiro textual previo, no que non é doado ancorarmos un discurso e estabelecermos referentes de asociación, e o enorme éxito instaurativo da súa proposta de reivindicación e reorientación do imaxinario outorgan un papel moi singular a este poemario de Rosalía como exemplo do poder do texto literario.

Un aspecto en que percibimos moi claramente a relación entre Rosalía e Cantares gallegos é precisamente o da súa forte relevancia para o imaxinario. Non só porque, como vimos, ambos padeceron os mecanismos propios de construción do imaxinario mediante operacións de redución, simplificación metonímica e mitificación; senón porque, sendo Rosalía a autora galega que, pola súa centralidade canónica, exemplifica mellor os procesos de mitificación, a construción dunha imaxe-tipo, o seu uso ideolóxico e a súa capacidade para ocultar e distanciarse do elemento sobre o que se constrúe, Cantares gallegos é unha obra literaria 
absolutamente abraiante na súa conciencia dos mecanismos retóricos que rexen o funcionamento dos imaxinarios (unha conciencia que se revela no prólogo e guía a construción da obra).

Esta perspectiva de análise permitiu superar algún dos tópicos condescendentes deitados sobre Cantares gallegos, como pode ser o das eivas estilísticas que se lle achacan e que, á luz da súa eficacia retórica en relación co imaxinario que contribúen a modificar, perde toda consistencia. Un exemplo desta actitude que estamos analizando atópase no xuízo de Marina Mayoral (1974: 321) a propósito da adxectivación en Rosalía. Esta autora manifestou o seu desgusto por un uso tópico, innecesario e redundante, que convive con outro que considera axeitado ${ }^{1}$ e sinalou, así mesmo, como esta profusión de adxectivos tende a concentrarse nas descricións da paisaxe (328-329). Claude-Henri Poullain (1974: 312-313) xulgou de xeito semellante a abundancia de epítetos no estilo de Rosalía: «hai que recońecer que, ás veces, a súa abundancia volve pesado o estilo [...]; nestes casos, o adxectivo é inútil e mesmo chega a constituír unha repetición; noutros poemas, a acumulación de epítetos é realmente excesiva».

Os estudos clásicos sobre imaxinarios sociais (Barthes 1958, Castoriadis 1974) asentaron a relevancia dos fenómenos de recorrencia para a súa instauración, perpetuación ou mudanza e, desde esta perspectiva, as cualificacións de inutilidade e repetición resultan manifestamente contraditorias. Deste xeito, algunha das críticas estilísticas acabou apuntando cara a funcionamentos retóricos que explican o éxito instaurativo que Cantares gallegos tivo na reorientación do imaxinario territorial e social galego.

Dun xeito semellante, apreciacións como a de Celso Almuíña Fernández (1986), quen lle achaca a Rosalía que «confunde a parte co todo» na súa representación de Castela, desmóntanse coa comprensión dos mecanismos do imaxinario, que actúan fortemente sobre a base de operacións metonímicas.

1 «El uso que de los adjetivos hace Rosalía hay que calificarlo de irregular. En conjunto produce la impresión de un poeta que no llega a darse cuenta plenamente del valor expresivo del instrumento que maneja. Tiene grandes aciertos y grandes errores o, por decirlo con palabras más objetivas, encontramos en sus versos adjetivos que por sí solos dan una imagen poética de la realidad, la elevan a categoría artística, y adjetivos tópicos, retóricos, que entorpecen con su vaho libresco la visión de las cosas. Y lo que es más raro, lo encontramos en poemas de una misma época» (Marina Mayoral 1974: 321). 


\section{CONCLUSIÓNS}

A historia crítica de Cantares gallegos é paralela da de Rosalía na dificultade para aceptar e integrar o plural. O debate sobre a primacía entre Cantares gallegos e Follas novas, o problema arredor da división da obra rosaliana en dúas linguas ou o tradicional relegamento dos seus escritos en prosa son consecuencia dunha dificultade para aceptar a Rosalía na súa totalidade e da tendencia a reducir e simplificar, implícita — cómpre dicir- nos mecanismos do imaxinario. O símbolo quérese que sexa inequívoco, simple, e Rosalía, pola súa enorme riqueza e por ser unha autora, xa non dobre, como sinalou Carvalho Calero, senón múltiple, e polo seu xogo coas contradicións, foi obxecto de reducións e apropiacións dun e doutro signo.

Esta historia crítica tan elocuente e digna de ser atendida de seu déixase sentir ata este mesmo ano de conmemoración e reivindicación de Cantares gallegos. Afirmabamos que a efeméride é o pretexto máis cá causa. Os últimos anos están sendo moi fértiles nunha atención a Rosalía que pretende corrixir nesgos e falsificacións, simplificacións inevitábeis nos procesos de mitificación, mais que resultaron sumamente lesivas para a personalidade creadora de Rosalía: desde a aceptación condescendente e minimizadora ata o engrandecemento compensatorio e mitificador. E velaí que, dentro deste movemento de explosión do mito, no contexto deste novo pulo por devolverlle a riqueza e complexidade inicial, insírese tamén unha nova ollada sobre Cantares gallegos. Quizais porque a conciencia que agora temos, á luz deitada polos últimos estudos, pon de relevo a enorme inxustiza que se fixo con eles. A mesma que coa Rosalía global: moi valorada pero reducida, domesticada e apropiada. Como sinalou Ramón Villares no prólogo á versión dixital da primeira edición de Cantares gallegos: «Nos tempos de hoxe podemos dicir que temos nesta poeta a verdadeira nai fundadora da Galicia contemporánea. E o libro Cantares gallegos abondaría de pedestal para soster esta inmensa estatua».

Poida que siga a ser preciso afirmalo; mais xa non o facemos, en calquera caso, sobre unha obra espontánea, popular, sentimental, irracional, propia dunha sensibilidade feminina; senón sobre unha produción complexa, subversiva, polifónica, feminista e eficaz, unha obra que soubo, desde o humilde texto literario, mudar as nosas percepcións e que se atreveu a enfrontarse a un imaxinario asentado, a 
máis poderosa construción ideolóxica que poida existir, e a pór en marcha o seu cambio. Fíxoo con ferramentas aparentemente sinxelas, procurando a ancoraxe axiolóxica alí onde podía atopala; pero engastándoa, deseguida, nunha construción retórica complexa e intelixente, servíndose do irracional e sentimental (porque sabía da súa eficacia), subvertendo, a miúdo, os valores dos cantares populares e situando no comezo un magnífico prólogo que sentou as bases do ensaísmo galego. 


\section{REFERENCIAS BIBLIOGRÁFICAS}

AA.VV. (1952): 7 ensayos sobre Rosalía, Vigo, Galaxia.

Almuíña Fernández, Celso (1986): «Rosalía e Castela / Castela e Rosalía», en Actas do Congreso internacional de estudios sobre Rosalía de Castro e o seu tempo, Santiago de Compostela, Consello da Cultura Galega I Universidade de Santiago de Compostela, III, 251-260.

Angueira, Anxo (2013): «Estudo introdutorio», en Cantares gallegos, Vigo, Xerais, 9-104.

Barthes, Roland (1957): «Mythologies», en Oeuvres complètes, París, Éditions du Seuil, I, 561-680.

Carvalho Calero, Ricardo (1975 [1963]): Historia da literatura galega contemporánea, Vigo, Galaxia.

Castoriadis, Cornelius (1975): L'institution imaginaire de la societé, París, Éditions du Seuil (2a edición revisada e corrixida).

Castro, Rosalía de (1866a): «Tipos gallegos. El cadiceño», Almanaque de Galicia, Lugo, Imprenta de Soto Freire, 73-82.

Castro, Rosalía de (1866b): «Ruinas. Desdichas de tres vidas ejemplares», El Museo Universal, Madrid, Imprenta de Gaspar y Roig, 9-71.

Castro, Rosalía de (1980, $1998^{6}$ [1880]): «Follas novas», en Poesía completa en galego. [Ed. de Benito Varela Jácome]. Vigo, Xerais, 197-359.

Castro, Rosalía de (1990 [1859]): La hija del mar, Padrón, Patronato Rosalía de Castro.

Castro, Rosalía de (1990 [1861]): Flavio, Padrón, Patronato Rosalía de Castro.

Castro, Rosalía de (2006 [1865]): «Las literatas. Carta a Eduarda», en El caballero de las botas azules. Lieders. Las literatas, Santiago de Compostela, Sotelo Blanco, 505-514.

Castro, Rosalía de (2013 [1863]): Cantares gallegos, Vigo, Xerais.

Feal Deibe, Carlos (1986): «Sobre el feminismo de Cantares gallegos», en Actas do Congreso internacional de estudios sobre Rosalía de Castro e o seu tempo, Santiago de Compostela, Consello da Cultura Galega / Universidade de Santiago de Compostela, I, 307-315.

Figueroa, Antón (1988): Diglosia e texto, Vigo, Xerais.

García CANDEIrA, Margarita (2012): «Más allá de la ansiedad de la autoría: poética del desierto, imaginación femenina y utopía en La hija del marn, en Helena González Fernández / María do Cebreiro Rábade Villar (eds.), Canon y subversión. La obra narrativa de Rosalía de Castro, Barcelona, Icaria, 99-120.

García Negro, María Pilar (2010): O clamor da rebeldía. Rosalía de Castro: ensaio e feminismo, Santiago de Compostela, Sotelo Blanco.

López SÁNDEz, María (2006): A descrición topográfica: o seu papel na construción dun imaxinario cultural no discurso literario galego (Cantares gallegos, Arredor de si e o ciclo textual de Tagen Ata), Santiago de Compostela, Universidade.

López SÁndez, María (2008): Paisaxe e nación: a creación discursiva do territorio, Vigo, Galaxia.

Lorenzana, Salvador (1952): "Xuicios Críticos sobre Rosalía», en AA. VV., 7 ensayos sobre Rosalía, Vigo, Galaxia, 151-171.

Mayoral, Marina (1974): La poesía de Rosalía de Castro, Madrid, Gredos.

PArdo BazÁn, Emilia (1888): De mi tierra, A Coruńa, Tipografía de la Casa de Misericordia.

Poullain, Claude Henri (1989 [1974]): Rosalía de Castro e a súa obra literaria, Vigo, Galaxia.

Sobrino Freire, Iria (2009): "Os prólogos a Cantares Gallegos e Follas Novas, manifestos por unha cultura da resistencia», en Rosalía 21, Vigo, Xerais, 37-42. 
